\title{
TIME METAPHORIZATION: DUALITY OF TIME AS A PURSUER VIS-À-VIS OBJECT OF PURSUIT
}

\author{
JACEK TADEUSZ WALIŃSKI \\ University of Lodz, Poland \\ jacek.walinski@uni.lodz.pl
}

\begin{abstract}
This paper discusses the duality of metaphorical conceptualizations of time focusing in particular on TIME AS A PURSUER and TIME AS AN OBJECT OF PURSUIT metaphors, which are based the Figure-Ground reversal of each other. Using examples taken from the British National Corpus, it argues that these metaphorical conceptualizations of time are inconsistent with each other. This inconsistency resembles the discrepancy between the MOVING TIME and MOVING OBSERVER metaphors, which are, in strict terms, also inconsistent with each other. Looking at such contrasts between metaphorical representations of time from a broader perspective suggests that the concept of time arises from different, both physical and socio-cultural, dimensions of human experience.
\end{abstract}

Keywords: time, motion, conceptual metaphor, cognitive corpus-based linguistics

\section{Introduction}

The problem of time perception is difficult to resolve because, in comparison to other dimensions of experience, time is quintessentially non-observable (Matthews and Meck 2014). Although numerous studies have demonstrated that the perception of time is subject to inter- and intra-individual variability, after over 125 years of research psychology has not distinguished a definitive sensory system responsible for the perception and processing of time (Hancock and Block 2012). Neither has research in neuroscience found the neural basis for the processing of temporal intervals and the experience of duration (Wittmann 2013). Different perspectives on time and temporality in language and cognition have been presented in abundant literature (e.g. Evans 2013; Lewandowska-Tomaszczyk and Kosecki 2014; Moore 2014; Waliński 2014 to mention but a few publications).

Almost fifty years ago Ornstein (1972) summarized the psychological problem of time experience in the following manner:

There is no process in the external world which directly gives rise to time experience, nor is there anything immediately discernible outside ourselves which can apprehend any special 
'time stimuli'. It is therefore not too surprising that psychological research on time as a dimension of consciousness has been so diverse, so incoherent, and so easily forgotten (Ornstein 1972: 96).

A few years later, Gibson (1975) ostensibly resolved this problem by pointing out that what we perceive are events in time, not time per se: "the perception of time is a puzzle of the same sort that the perception of space has been - an insoluble one. There is no such thing as the perception of time, but only the perception of events and locomotions" (Gibson 1975: 295).

Lakoff and Johnson (1980, 1999: 138) used this point of view to define time as a metaphorical and metonymical phenomenon relating to recurrence of events (cf. Evans 2003, Ch. 2). They proposed that, because time as such is nonobservable, we conceptualize time metaphorically and metonymically in terms of other entities that are more accessible to the senses (Lakoff and Johnson 1980, 1999; Fauconnier and Turner 2008).

More recently, Szwedek $(2009,2011)$ proposes an alternative perspective on the metaphorical conceptualization of time, namely the theory of objectification, which questions the metaphorical schemas viewing time in terms of space, motion, and other non-physical entities. He sees physical object as the ultimate source domain and postulates that instead of the TIME AS SPACE metaphor we should consider the TIME AS AN OBJECT (IN SPACE) metaphor, and instead of the TIME AS MOTION metaphor we should consider the TIME AS AN OBJECT (IN MOTION) metaphor. Szwedek (2011) argues that reducing conceptualizations of time to the single interpretation of TIME AS AN OBJECT enables us to eliminate the inconsistencies between temporal metaphors (cf. Lakoff and Johnson 1999: 141148).

At the same time, a contrasting position on the metaphorical conceptualization of time has been proposed by Galton (2011), who argues that spatial metaphors can never do justice to the nature of time as a basic feature of the human experience. He observes that all temporal metaphors take some kind of change as their source, which means that they depend on the fundamental feature of temporal transience. Galton assumes that transience can be described as fleetingness, i.e. the idea that we only experience a time at the time we are experiencing it (see also Bergson 1922/2002). We say "What's done is done", "You only live once", etc. because any given moment occurs only once, at that very moment of time, and any given time is only present when it is that time.

It seems that these two recent positions mark two opposite ends on a spectrum of views on the conceptualization of time. On one pole of the spectrum, Szwedek's $(2009,2011)$ theory of objectification attempts to reduce conceptions of time to material objects that can be captured directly through the senses because of their tangibility. On the other end, Galton's (2011) position of temporal transience lays emphasis on time as immaterial dynamic process that relentlessly escapes sensory perception, thus can only be captured indirectly through changes of states observable in time. Yet, neither of these proposals seems to be entirely capable of 
providing a definitive account of the nature of conceptualizations of time. This paper discusses a contrast between TIME AS A PURSUER and TIME AS AN OBJECT OF PURSUIT metaphors, which function as a pair of conceptualizations based on the Figure-Ground reversal of each other. Using data from the British National corpus, it demonstrates that these two metaphorical conceptualizations are, at least in strict terms, inconsistent with each other.

\section{Variety of metaphorical conceptualizations of time}

Lakoff and Johnson (1999: 138) define the conceptualization of time as a metonymical phenomenon relating to recurrence of events. "In the world, there are iterative events against which other events are compared ... Successive iterations of a type of event stand for intervals of time" (Lakoff and Johnson, 1999: 138). The metonymical conceptualization of time is reflected not only in language but also in other cultural artifacts related to time, such as: sundials, hourglasses, clocks, calendars, time lines, etc., which serve as material anchors mirroring the way we think about time (Fauconnier and Turner 2002: 194-198; Hutchins 2005; Lakoff and Johnson 1999: 155-156; Williams 2004).

However, Evans (2003) argues that our conceptions of time may not relate as much to the awareness of changes perceptible in events, but rather to the subjective experience of duration. He asserts that "we actually experience the 'passage' of time whether there has been a change in the world-state or not" (Evans, 2003: 64). On this account, the ability to experience duration is a prerequisite for the awareness of change, not vice-versa.

As noted by Langacker (2012: 203), because time is intricate to describe or even think about, it remains an open question whether we directly experience time or our temporal experience is limited to merely observing the succession of events. However, Langacker (2012: 191-192) assumes that in order to properly interpret linguistic evidence in relation to time we need to distinguish two different levels of temporal experience. The level of basic experience reflects our biological aptitude of organisms potentially capable of experiencing time passage, which can be reasonably presumed to be comparable among all human beings. As a fundamental cognitive aspect of temporality, it functions as an organic medium for apprehension of other entities.

On the other hand, at the level of interpreted experience time is the product of cultural elaboration and transfer from generation to generation. This conscious kind of temporal experience is derived from time as an object of conception and analysis. Langacker notes that both individual and culturally constructed conceptions of time are significantly influenced by a variety of socio-cultural frames reflecting ideas and patterns widely held and used in the society. Consequently, the interpreted experience of time is complex, multifaceted and highly variable. 
Notwithstanding these alternative dimensions of experience, the conceptualization of time takes place through mediation of other concepts that are more tangible to human senses. Lakoff and Johnson (1999: 52) point out that time is often conceptualized through perceptual and motor experience in the concrete domain of space as the TIME IS MOTION metaphor in two major variants: motion of objects and motion along a path. With the MOVING TIME metaphor (Lakoff and Johnson 1999: 141-144), we conceive of ourselves as stationary, with events approaching us from the future, e.g. "the coming weeks", "the deadline is approaching", etc. In contrast, with the MOVING OBSERVER metaphor (Lakoff and Johnson 1999: 145-148), time is conceived of as a stationary landscape, along which we are moving, encountering events as we proceed, e.g. "we are approaching the deadline", "leave your childhood behind", etc. Our choice of the metaphorical mapping in a given situation appears to be strongly affected by thinking about the way physical objects move in space (Boroditsky and Ramscar 2002).

These two different assignments of front/back to the timeline have been discussed in ample literature on conceptions of time (e.g. Lakoff and Turner 1989; Evans 2003; Radden 2004; Moore 2006, 2014). Lakoff and Johnson (1999: 148149) point out that the MOVING TIME and MOVING OBSERVER metaphors are, strictly speaking, inconsistent with each other. However, they can be viewed as minimally differing variants based on Figure-Ground reversal of the more general TIME IS MOTION metaphor. Metaphors commonly come in duals based on figureground reversal. Lakoff and Johnson (1999: Ch. 11) view the phenomenon of metaphorical duality as a general attribute of EVENT-STRUCTURE concepts, such as state, action, and cause.

Moore $(2006,2014)$ points out that there is a third, largely overlooked type of time as motion metaphor that relates two times to each other independently of ego's perspective. Instead of using a deictic reference to ego, it locates a particular time relative to another time. In that metaphor, time is depicted as being in an unchanging relationship of sequence in which the intervals between times do not change, which corresponds to the tenseless view of time (McTaggart 1908; see also Smart 2008). From this perspective, New Year always follows Christmas but never gets closer to it. Thus, Moore $(2006,2014)$ proposes a division of the MOVING TIME metaphor into two metaphorical variants: EGO-CENTERED MOVING TIME, which is perspective specific, and SEQUENCE IS RELATIVE POSITION ON A PATH, which is perspective neutral.

Another prevalent metaphorical conceptualizations of time include TIME AS A RESOURCE and TIME AS MONEY metaphors (Lakoff and Johnson 1980: 7-9, 1999: 161-164; Evans 2003: Ch. 14). They impose an outlook in which we use time in manners similar to how we use money or valuable resources in general, hence time can be spent, given, borrowed, lost, wasted, etc. This metaphor, however, belongs to the category of socio-cultural constructs, rather than universal aspects 
of human cognition, since it appears in some languages and societies, but not others (Everett 2005; Idström 2010; Kövecses 2005).

Moreover, metaphorical conceptions of time frequently entail personification, which "allows us to comprehend a wide variety of experiences with non-human entities in terms of human motivations, characteristics, and activities" (Lakoff and Johnson 1980: 33). Lakoff and Turner (1989: 35-43 and 73-79; see also Kövecses, 2010: 55-56) discuss common conceptualizations of time based on the TIME AS A CHANGER metaphor (in more specific variants such as DESTROYER, Devourer, ReAPer, Evaluator, HEAler, THIEF), where time is conceptualized as an entity largely independent of events it influences. Evans (2003: Ch. 12) argues that the personification represents a separate sense of time. In this sense, which he labels Agentive Sense, time is conceived not just as an entity serving to manifest change but as a causal agent of change that appears to be actively involved in the occurrence of specific events. This restricts, at least to some extent, the nature of the agentive imagery that can be employed to elaborate this sense. Time cannot be fleshed out by just any kind of agent but requires specific kinds of agents with a particular skill or ability to affect us (Evans 2003: 164-165). This study discusses another specific variant of the agentive metaphorical personification of time in which it is conceptualized as a PURSUER. The discussion is conducted from the perspective of the conceptual metaphor theory illustrated with examples taken from linguistic corpora.

\section{Cognitive corpus-based approach to metaphor study}

This study approaches the problem of metaphorical conceptions of time from the perspective of cognitive usage-based approach to language study (Tummers, Heylen, and Geeraerts 2005), which brings together the descriptive framework of cognitive linguistics with the methodological workbench of corpus linguistics. More specifically, it employs a corpus-illustrated approach, in which the corpus data are used for the selection of examples to validate intuitive interpretation. As emphasized by Deignan (2008: 293), grounding research on the conceptual metaphor in the corpus data "can reveal many linguistic details that could be passed over in the examination of single texts, and might not be observed at all when data are elicited rather than gathered from language in use".

This research employs the British National Corpus (henceforth, the BNC), which is a 100 million word collection of samples of written and spoken contemporary British English from a wide range of texts, not limited to any particular subject field, genre, or register (see www.natcorp.ox.ac.uk for more information). From an array of different strategies that can be used for extracting linguistic expressions that reflect conceptual metaphorical mappings from corpora (see Stefanowitsch 2006 for a review), this study employs searching for sentences containing lexical items from both the source domain and the target domain. More 
specifically, the examination was implemented by looking for expressions in which verbs relating to the concept of pursuit, as the conceptual source domain, either precede or follow lexemes used to refer to time, as the metaphorical target domain investigated in this study. Eight verbs relating to the activity of pursuit were selected for analysis, i.e. catch, chase, hurry, press, prompt, pursue, race, and urge. They were employed for queries in the 1st and 3rd person present, past, and participial forms, e.g. pursue, pursues, pursued, pursuing, to account for a variety of linguistic expressions.

Selecting suitable lexical items from the target domain followed observations (Evans 2003; Langacker2012) that time functions in language in several different manners. On the one hand, it is an abstract entity expressed by a mass noun, e.g. much time, enough time, more time, etc., but also appears as a bounded entity in complex expressions that designate a certain point in time, e.g. instant, moment, etc., or an interval of time, e.g. period, span of time, length of time, etc. Moreover, there are also numerous expressions that designate temporal points or intervals indirectly. These include both common nouns referring to temporal units, such as minute, hour, day, week, etc., and proper nouns like Monday, January, and 1812. For this study, ten lexemes used to refer to time, namely: time, deadline, hour, moment, occasion, past, period, span, spell, and term were selected in both singular and plural forms. This combination of verbs and nouns includes 640 variants ( 32 verb forms $\times 20$ noun forms).

The searching was implemented with proximity queries (Bernard and Griffin 2009). They allow for searching with a slope value, which specifies how far apart lexical items included in a query can be from one another to be still returned as a result to the query. Moreover, the slope can be used in combination with the binary (yes/no) preserve order option, which indicates whether the original order of query terms should be retained in results. In this study, the proximity queries were implemented with the slope value of 3 and the preserve order option set to "no". This allows for finding both examples of time functioning as a PURSUER, e.g. "Time is catching up on us", and those where time functions as an OBJECT OF PURSUIT, e.g. "We need to catch up on lost time", with a single query. It increases the number of variants taken into consideration to 5120 (640 basic variants $\times 4$ slope options [0-3 separating lexemes] $\times 2$ possible orders [noun-verb or verbnoun]). Although far from being exhaustive of possible linguistic representations of the metaphors under investigation, it seems to be reasonably adequate for the purpose of this study.

Corpus queries based on the above lexical pattern returned 1315 matching concordance lines from the BNC. Since the search was implemented with a large value of slope, which increases the recall of the results at the expense of their precision (see Pęzik 2011), the resulting set had to be reviewed to exclude matches sharing the linguistic pattern by coincidence. As a result, 97 examples were recognized as valid representations of the temporal metaphors, with 31 
representations found for the TIME AS A PURSUER and 66 representations for the TIME AS AN OBJECT OF PURSUIT metaphor, respectively.

\section{TIME AS A PURSUER}

The metaphorical conception of time as a PURSUER has been discussed in cognitive linguistic studies rather sparsely. An example of the metaphor that depicts time as a motive force that impels us forward from behind appears in Andrew Marvell's (1681/1936) poem To his Coy Mistress:

\footnotetext{
But at my back I always hear

Time's winged chariot hurrying near;

And yonder all before us lie

Deserts of vast eternity.
}

In their guide to poetic metaphors, Lakoff and Turner (1989: 46) quote this poem coupled with Aeschylus' adage "Time overtakes all things alike" to argue that such expressions depict time as a relentless, unnerving pursuer whom we try to avoid by running away. Yet, since the pursuer ultimately cannot be outrun, our efforts are taken in vain. They add that this metaphor functions in ordinary language within a conglomerate of metaphors related to life, death, and time, which includes such metaphors as EVENTS ARE ACTIONS, TIME MOVES, and LIFE IS A JOURNEY. More recently, Ruiz de Mendoza Ibáñez and Barreras Gómez (2015) also see the stanza as the implication that when time catches up with people, they are affected by it in terms of aging and death.

The personification of time goes back to early Greek culture, where time both as Aion, i.e. time in its absolute eternal sense, and Kronos, i.e. the empirical time divided into past, present, and future in relation to human life, were depicted in terms of human figures (Stafford and Herrin, 2005). Pettazzoni (1954) argues that both Aion and Kronos were two different interpretations of the ancient Egyptian conception of endless time personified as the Sun-god, who was believed to command the chariot that rode across the sky during the day. In the early Renaissance those ancient personifications of time were imported into the Western art, literature, and culture (Cohen 2000), which profoundly affected popular conceptions of time. It was only after the Industrial Revolution when the global transition to clock time took place and societies started to function according to the universal "standard" time, which transformed time into a valuable commodity (Landes 2000). Perhaps less common nowadays than it used to be, the metaphor of TIME AS A PURSUER still functions in this day and age, which is exemplified by the following quote form Daily Mail Online:

Wimbledon champion Novak Djokovic forced 30-year-old Roger Federer to accept that time has caught up with him after producing a remarkable comeback... (Folley, 2011). 
The basic meaning of time catching up with us is that we are getting older. Additional examples of time hurrying us to aging and death were identified with Google Books Ngram Viewer. They demonstrate that time acts as the unstoppable agent that brings about decay and fading away, e.g. "The impetuous current of time hurries mortals, as in a sleep, into eternity", "Time hurries on in spite of all the reluctance of mankind", "Time hurries us forward, and eternity as with slow and solemn tread, comes forward to receive us". In all these expressions time hurries us to the inevitable end of our earthly existence.

However, other examples found in the BNC demonstrate that time conceived of from the perspective of a PURSUER can also be conceptualized in more specific ways. For instance, time presses us to take certain actions, as in "Shall we make a start because the time's pressing on?", "Time presses on, I must dash...". Sometimes it prompts us to act quickly, as in "Name them quickly, for time presses". Moreover, it may exert influence on the course of our actions, e.g. "Excuse me, but as you know, time presses; and I want to keep our question on the straightest line possible". Sometimes, it may affect the spatial route to a destination point, e.g. "But if time presses, you can take a direct road from Frauenfeld". In other scenarios, it forces us to take quick decisions, e.g. "Time presses a decision on them without delay", typically because of "pressing deadlines", even if we are not entirely ready to take them, as in "decisions have to be made in conditions of acute uncertainty, under pressing deadlines". The pressure of time can also serve as an excuse, as in "That is kind of you, Dauntless said firmly, but time presses".

Kövecses (2010: 56) emphasizes that the fundamental question arising in the context of time personification is why we use the kinds of persons as the source domains to understand time. A plausible answer to this question for the TIME AS A PURSUER metaphor is that, on the one hand, it reflects the universal destructive nature of time as a DESTROYER that causes inevitable decay of all things and aging, which ultimately leads to death. On the other hand, time prompts us to take decisions and actions relevant to our immediate course through the lifetime, which relates to the LIFE IS A JOURNEY metaphor. This, however, does not exhaust the full characteristics of this metaphorical conception of time, as it is accompanied by an additional variant in which time functions as an object of pursuit.

\section{TIME AS AN OBJECT OF PURSUIT}

The TIME AS A PURSUER metaphor, which draws on motion in the source domain, appears to be accompanied by the variant in which time functions as an OBJECT OF PURSUIT. Lakoff and Johnson (1999: Ch. 10-11) demonstrate that the potential for shifting Figure and Ground is realized quite commonly in metaphors relating to EVENT STRUCTURE. They term such pairs as duals and the phenomenon as 
duality. Because Figure and Ground are not features of mind-independent reality but merely aspects of human cognition, a shift in their orientation is nothing unusual (Thiering 2015: Ch. 3).

More specifically, this dual swaps the roles between Agent and Theme. While in the TIME AS A PURSUER metaphor time is conceptualized as an agent capable of endless pursuit, in the TIME AS AN OBJECT OF PURSUIT metaphor it is us who take the role of agents actively chasing time as a moving object that is running away from us. Removing time from the active position of an agent lends some intriguing properties to the concept of time. It no longer has to be something unnerving, predestinate, and dooming. Instead, at least in certain scenarios, time can be conceptualized as something (or someone) that is desired, precious, worthy of pursuit.

Looking at the TIME AS AN OBJECT OF PURSUIT metaphor through the lens of the examples found in the BNC shows that we often try to catch time for banal reasons, for instance, to get some extra time for sleep, as in "he climbed back into bed, hoping to catch another hour of sleep". We also catch up time to make up for the lost time, e.g. to avoid being late, as in "She congratulated herself that she had caught up time, and was now only half an hour late". Interestingly, catching up on lost time seems to be possible not only for humans but also for other living organisms, such as communities of people, e.g. "the village has now caught up with modern times", and plants, whose growth was found in the BNC to be described as follows: "when it does get going soon catches up on lost time".

Moreover, although the odds of winning a "race against time" rarely look favorable, in some particular cases it can be won, as in "[The team of] Wolves have won a race against time" or "Technical staff won a race against time to get their set up for their presentation...". In such scenarios, deadlines are met or targets are reached in time. Furthermore, a race against time is taken up not only out of necessity, e.g. by doctors trying to save lives, but also out of ambition, e.g. by journalists "racing against deadlines" to deliver the latest scoop and by managers "chasing deadlines" to complete their plans.

In such contexts, time is conceptualized as a desired object that is running away from the pursuer, and the pursuer is trying to move closer or race with the object until they catch up or overtake it. It parallels, to some extent, the metaphor HAPPINESS IS A DESIRED OBJECT, which has recently been analyzed by Kövecses (2015: 166-169) for the phrase "the pursuit of happiness". Using that analysis as a model, the following mappings can be proposed for the TIME AS AN OBJECT OF PURSUIT metaphor:

The desired object $\rightarrow$ time in the sense of obtaining extra time/making up for the lost time/meeting a deadline/being up to date with modernity The movement (of the object) $\rightarrow$ the difficulty of obtaining the desired time away from us

The pursuer (of the object) $\rightarrow$ the person (trying to obtain the desired time) The pursuit (of the object) $\rightarrow$ trying to catch up with or overtake (the object) 
The desire (to catch or overtake the object) $\rightarrow$ the desire for obtaining extra time/making up for the lost time/meeting a deadline/being up to date with modernity

Catching the object $\rightarrow$ success in obtaining the desired time

The idea of motion towards the destination underlying this metaphor provides for a partial overlap with another common metaphor LIFE IS A JOURNEY. Given this metaphor, a successful life depends on reaching our immediate or more distant destinations, i.e. our life goals. Achieving such goals involves "gaining time", "catching up on lost time", "getting ahead of time", etc. (cf. Kövecses 2015: 167 for parallels between the HAPPINESS IS A DESIRED OBJECT and the LIFE IS A JOURNEY metaphors).

Fauconnier (1997: 25-33) discusses the complex conceptual mappings involved in the expressions of catching up on time. He argues that the prototype for such expressions involves "two entities moving along the same path, and a time interval during which one of them is behind the other and at the end of which they are at the same point on the path" (Fauconnier 1997: 25). He adds that the path does not necessarily have to be spatial, it can be a common virtual path. Using such expressions, the speaker says that they managed to get some scheduled activities done in a time shorter than had been left at some earlier point in time. Although such expressions are based on TIME/SPACE metaphorical mappings, events can also be mapped because they can be associated with a time point or time interval (see Langacker 2008: 355-60; 2012). It gives rise to such temporal expressions as "to keep up with the times", "fall behind the times", "to be ahead of one's time".

Fauconnier (1997) emphasizes that the conceptual construction behind such expressions is complex. They involve motion on several levels: the times move, and the individuals move. Additionally, on a third level, there are the events socioculturally associated with their times. At any given time, a person is linked to the event they are actually engaged in and to the event they should be engaged in according to the schedule. Accordingly, there exist many different conceptual mappings: one mapping links individuals with times at which they live; another links events with the times socio-culturally associated with them; a third links individuals to events they engage in. Therefore, a person moves on two correlated paths: the path of real time and the path of scheduled events. This triggers the inference that someone can be engaged in activities scheduled for a time earlier/later than the one they are living at a particular moment in time. An individual can therefore be conceptualized as being behind or ahead of his/her time. Catching up implies a repositioning on the temporal scale to the expected position in time. Such mappings have pragmatically determined values functioning among members of the same culture who share the concept of scheduling. What must be strongly emphasized is that such expressions trigger socio-cultural rather than physical time scales. 


\section{Conclusions}

The examples found in the BNC demonstrate that the duality between the TIME AS A PURSUER and TIME AS AN OBJECT OF PURSUIT metaphors offers a potential for time to be conceptualized from outright contrasting perspectives. On the one hand, time can be conceptualized as an active willful agent that cannot be outrun to escape aging and death. On the other hand, time conceptualized as an object running away from us can be, at least in some scenarios, caught up with, e.g. to meet deadlines, attain objectives, fulfill ambitions, etc., or even overtaken, which is exemplified by sentences such as "we are a little ahead of time, we're certainly going to complete the business" (found in the BNC). However, the examples found in the BNC indicate that we do not pursue time in the sense of eternity (cf. the unbounded Matrix sense in Evans 2003: Ch. 11), but rather some specific moments or occurrences in time (cf. Moment and Event senses of time in Evans, 2003: Ch. 8 and 10). Those different senses seem to separate these antithetical metaphorical conceptualizations.

The contrast between the TIME AS A PURSUER and TIME AS AN OBJECT OF PURSUIT resembles the discrepancy between the above-discussed MOVING TIME and MOVING OBSERVER metaphors, which are also inconsistent with each other. In broader terms, this metaphorical duality parallels, at least to some extent, the duality of perspectives taken to time in the following the example provided by Fauconnier and Turner (2008):

\footnotetext{
"Time goes by really slowly. At the same time, it goes by really fast." (CNN, said by a man waiting for word on an American named "Michael" missing in the bomb detonations in London in July 2005.)
}

A possible interpretation of this sentence reads that "time is going by too slowly because Michael is not showing up, but time is going by too fast because the likelihood that Michael is dead increases with every passing minute" (Fauconnier and Turner 2008: 61). This example shows that a specific situation can evoke opposing subjective dimensions of time experience in a single person.

A question arising naturally in the context of such contrasting cognitive perspectives taken to time is to what extent the nature of time in linguistic construal hinges on the implicit and explicit embodiment of time (Boroditsky and Ramscar 2002; Kranjec and McDonough 2011) and to what extent depends on the socio-cultural elaboration and transfer from generation to generation. It seems that the rigidity of the conceptual structuring of time is established, as least for some part, by the patterns of commonly used phraseology, rather than by conceptual restrictions as such. This can be attributed to sedimentation of meaning (Woelert 2011) understood as the linguistic consolidation of cognitive structures originally given in embodied sense-experience through certain persisting linguistic conceptualizations superimposed by language acquisition and cultural 
transmission. The duality of temporal metaphors demonstrated in this paper suggests that time as the conceptual establishment expands beyond the natural physical dimension of the universe and the socio-cultural dimension of experience created in the minds of a linguistic community, despite sharing a facet with both of them. Looking at such inconsistencies from a wider perspective suggests that it belongs to a specific category of conceptual phenomena. Approaching time from a separate angle may be a key element required to establish a universal cognitive conception of time that fully explains its nature in linguistic construal.

\section{References}

Bergson, Henri. 1889/2001. Time and Free Will, an Essay on the Immediate Data of Consciousness [First published in 1889]. New York: Dover.

Bernard, Emmanuel and John Griffin. 2009. Understanding Lucene's query syntax. In Hibernate Search in Action, 202-214. Greenwich, CT: Manning.

Boroditsky, Lera and Michael Ramscar. 2002. The Roles of Body and Mind in Abstract Thought, Psychological Science, 13(2), 185-189. https://doi.org/10.1111/1467-9280.00434

Cohen, S. 2000. The early Renaissance personification of Time and changing concepts of temporality. Renaissance Studies, 14(3), 301-328. https://doi.org/10.1111/1477-4658.00339

Deignan, Alice. 2008. Corpus Linguistics and Metaphor. In Raymond W. Gibbs (ed.), The Cambridge Handbook of Metaphor and Thought, 280-294. Cambridge: Cambridge University Press. https://doi.org/10.1017/CBO9780511816802.018

Evans, Vyvyan. 2003. The Structure of Time: Language, meaning and temporal cognition. Amsterdam: John Benjamins. https://doi.org/10.1075/hcp.12

Evans, Vyvyan. 2013. Language and Time: A Cognitive Linguistics Approach. Cambridge: Cambridge University Press. https://doi.org/10.1017/CBO9781107340626

Everett, Daniel L. 2005. Cultural Constraints on Grammar and Cognition in Piraha: Another Look at the Design Features of Human Language. Current Anthropology, 46(4), 621-646. https://doi.org/10.1086/431525

Fauconnier, Gilles. 1997. Mappings in Thought and Language. Cambridge: Cambridge University Press. https://doi.org/10.1017/CBO9781139174220

Fauconnier, Gilles and Mark Turner. 2002. The Way We Think: Conceptual Blending and the Mind's Hidden Complexities. New York: Basic Books.

Fauconnier, Gilles and Mark Turner. 2008. Rethinking metaphor. In Raymond W. Gibbs (ed.), The Cambridge Handbook of Metaphor and Thought, 53-66. Cambridge: Cambridge University Press. https://doi.org/10.1017/CBO9780511816802.005

Galton, Antony. 2011. Time flies but space does not: Limits to the spatialisation of time. Journal of Pragmatics, 43(3), 695-703. https://doi.org/10.1016/j.pragma.2010.07.002

Gibson, James J. 1975. Events are Perceivable But Time Is Not. In J. T. Fraser and N. Lawrence (eds.), The Study of Time II: Proceedings of the Second Conference of the International Society for the Study of Time, 295-301. Berlin: Springer. https://doi.org/10.1007/978-3-642-501210_22

Hancock, Peter A. and Richard A. Block. 2012. The Psychology of Time: A View Backward and Forward. American Journal of Psychology, 125(3), 267-274. https://doi.org/10.5406/ameripsyc.125.3.0267

Husserl, Edmund. 1939/1970. The Origin of Geometry. In The Crisis of European Sciences and Transcendental Phenomenology: An Introduction to Phenomenological Philosophy [First published in 1939], 353-378. Evanston, IL: Northwestern University Press. 
Hutchins, Edwin. 2005. Material anchors for conceptual blends. Journal of Pragmatics, 37(10), 1555-1577. https://doi.org/10.1016/i.pragma.2004.06.008

Idström, Anna. 2010. What Inari Saami idioms reveal about the time concept of the indigenous people of Inari. Yearbook of Phraseology, 1(1), 159-178. https://doi.org/10.1515/9783110222623.1.159

Kövecses, Zoltán. 2005. Metaphor in Culture: Universality and Variation. Cambridge: Cambridge University Press. https://doi.org/10.1017/CBO9780511614408

Kövecses, Zoltán. 2010. Metaphor: A Practical Introduction, 2nd Ed. New York: Oxford University Press.

Kövecses, Zoltán. 2015. Where Metaphors Come from: Reconsidering Context in Metaphor. New York: Oxford University Press. https://doi.org/10.1093/acprof:oso/9780190224868.001.0001

Kranjec, Alexander and Laraine McDonough. 2011. The implicit and explicit embodiment of time. Journal of Pragmatics, 43(3), 735-748.

Lakoff, George and Mark Johnson. 1980. Metaphors We Live By. Chicago: University of Chicago Press.

Lakoff, George and Mark Johnson. 1999. Philosophy in the Flesh: The Embodied Mind and Its Challenge to Western Thought. Chicago: University of Chicago Press.

Lakoff, George and Mark Turner. 1989. More Than Cool Reason: A Field Guide to Poetic Metaphor. Chicago: University of Chicago Press. https://doi.org/10.7208/chicago/9780226470986.001.0001

Landes, David S. 2000. Revolution in Time: Clocks and the Making of the Modern World. Cambridge, MA: Harvard University Press.

Langacker, Ronald W. 2008. Cognitive Grammar A Basic Introduction. Oxford: Oxford University Press. https://doi.org/10.1093/acprof:oso/9780195331967.001.0001

Langacker, Ronald W. 2012. Linguistic manifestations of the space-time (dis)analogy. In Luna Filipović and Kasia M. Jaszczolt (eds.), Space and Time in Languages and Cultures: Language, culture, and cognition, 191-215. Amsterdam: John Benjamins. https://doi.org/10.1075/hcp.37.15lan

Lewandowska-Tomaszczyk, Barbara and Krzysztof Kosecki (eds.). 2014. Time and Temporality in Language and Human Experience. Frankfurt am Main: Peter Lang. https://doi.org/10.3726/9783-653-03331-1

Matthews, William J. and Warren H. Meck. 2014. Time perception: the bad news and the good. Wiley Interdisciplinary Reviews: Cognitive Science, 5(4), 429-446. https://doi.org/10.1002/wcs.1298

McTaggart, J. Ellis. 1908. The Unreality of Time. Mind, XVII(4), 457-474. https://doi.org/10.1093/mind/XVII.4.457

Moore, Kevin E. 2006. Space-to-time mappings and temporal concepts. Cognitive Linguistics, 17(2), 199-244. https://doi.org/10.1515/COG.2006.005

Moore, Kevin E. 2014. The Spatial Language of Time: Metaphor, Metonymy, and Frames of Reference. Amsterdam: John Benjamins. https://doi.org/10.1075/hcp.42

Ornstein, Robert E. 1972. The Psychology of Consciousness. Harmondsworth: Penguin Books.

Pettazzoni, Raffaele. 1954. Aion - (Kronos) Chronos in Egypt. In Raffaele Pettazzoni (ed.), Essays on the History of Religions, 171-179. Leiden: Brill.

Pęzik, Piotr. 2011. Providing corpus feedback for translators with the PELCRA search engine for NKJP. In Stanisław Goźdź-Roszkowski (ed.), Explorations Across Languages and Corpora: PALC 2009, 135-144. Frankfurt am Main: Peter Lang.

Radden, Günter. 2004. The metaphor TIME AS SPACE across languages. In N. Baumarten, C. Böttger, M. Motz, and J. Probst (eds.), Übersetzen, Interkulturelle Kommunikation, Spracherwerb und Sprachvermittlung - das Leben mit mehreren Sprachen, 225-238. Bochum: AKS-Verlag. 
Ruiz de Mendoza Ibáñez, Francisco J. and María A. Gómez. 2015. Time and Cognition in Marvell’s 'To his Coy Mistress'. Cognitive Semantics, 1(2), 241-260. https://doi.org/10.1163/2352641600102004

Smart, John J. C. 2008. The Tenseless Theory of Time. In T. Sider, J. Hawthorne, and D. W. Zimmerman (eds.), Contemporary Debates in Metaphysics, 226-238. Malden, MA: Blackwell.

Stafford, Emma and Judith Herrin (eds.), 2005. Personification in the Greek World: From Antiquity to Byzantium. Aldershot: Ashgate.

Stefanowitsch, Anatol. 2006. Corpus-based approaches to metaphor and metonymy. In Anatol Stefanowitsch and Stefan T. Gries (eds.), Corpus-Based Approaches to Metaphor and Metonymy, 1-16. Berlin: Mouton de Gruyter. https://doi.org/10.1515/9783110199895

Szwedek, Aleksander. 2009. Conceptualization of space and time. In Piotr Łobacz, Władysław Zabrocki and Piotr Nowak (eds.), Language, Science and Culture, 317-333. Poznań: Wydawnictwo Naukowe UAM.

Szwedek, Aleksander. 2011. The ultimate source domain. Review of Cognitive Linguistics, 9(2), 341-366. https://doi.org/10.1075/rcl.9.2.01szw

Thiering, Martin. 2015. Spatial Semiotics and Spatial Mental Models: Figure-Ground Asymmetries in Language. Berlin: De Gruyter Mouton. https://doi.org/10.1515/9783110356878

Waliński, Jacek T. 2014. Complementarity of Space and Time in Distance Representations: A Cognitive Corpus-based Study. Łódź: Łódź University Press. https://doi.org/10.18778/7969441-9

Williams, Robert F. 2004. Making meaning from a clock: Material artifacts and conceptual blending in time-telling instruction. (Ph.D. Dissertation). University of California, San Diego.

Wittmann, Mark. 2013. The inner sense of time: how the brain creates a representation of duration. Nature Reviews Neuroscience, 14(3), 217-223. https://doi.org/10.1038/nrn3452

Woelert, Peter. 2011. Human cognition, space, and the sedimentation of meaning. Phenomenology and the Cognitive Sciences, 10(1), 113-137. https://doi.org/10.1007/s11097-010-9153-3

\section{Literary and journalistic texts}

Folley, Malcolm. 2011, September 10. What a Djoker! Novak comes through epic semi-final after Federer blows his big chance. Mail Online. [Online] Available from: www.dailymail.co.uk/sport/tennis/article-2036060/What-Djoker-Novak-comes-epic-semifinal-Federer-blows-big-chance.html [Accessed: 30th January 2017].

Marvell, Andrew. 1681/1936. To His Coy Mistress [Poem first published in 1681, anthology first published in 1918]. In Arthur Quiller-Couch (ed.), The Oxford Book Of English Verse, 12501900, 387-388. Oxford: Clarendon Press.

\section{Corpora and resources}

British National Corpus. 2001. [World Edition] Available from OUCS at: http://www.natcorp.ox.ac.uk

Google Books Ngram Viewer. 2017. Available at: https://books.google.com/ngrams

SlopeQ. 2012. A part-of-speech-sensitive concordancer with support for proximity queries for the British National Corpus. [Developed by Piotr Pęzik]. Łódź: University of Łódź. 